\title{
EVALUATION OF ANTHELMINTIC ACTIVITY USING SOLVENT EXTRACT OF PADINA TETRASTROMATICA IN INDIAN EARTHWORM (PHERETIMA POSTHUMA)
}

\author{
B. Clara Gnana Selvi ${ }^{1}$ and Amutha Santhanam ${ }^{1,2,{ }^{*}}$ \\ ${ }^{1}$ Department of Biotechnology, Thiruvalluvar University, Vellore-632 115, India \\ ${ }^{2}$ National Centre for Nanoscience and Nanotechnology, Guindy campus, University of Madras, \\ Chennai-600 025, India
}

\begin{abstract}
The anthelmintic activities of different solvent extracts of Padina tetrastromatica were evaluated on Indian adult earthworms Pheretima posthuma (Annelida). Different concentrations (50 and $100 \mathrm{mg} / \mathrm{ml}$ ) of methanolic, diethyl ether and aqueous extracts were evaluated for anthelmintic activity by recording the time required for paralysis and death of earthworms. The activities were compared with the standard drug Albendazole. Dose-dependent activity was observed in the solvent extracts of seaweed. However, the methanolic extract of seaweed Padina tetrastromatica showed significant anthelmintic activity than the standard drug.
\end{abstract}

Keywords: Padina tetrastromatica, Pheretima posthuma, Anthelmintic, Methanolic extract.

\section{INTRODUCTION}

Current research on macro algae-derived compounds that showed a broad range of biological activities such as antiviral, antineoplastic, antibacterial, antifouling, antiinflammatory, antifungal, cytotoxic and antimitotic activities (1). Helmintic infections are among the most widespread infections in humans, distressing a huge population of the world. The gastro-intestinal helminths becomes resistant to currently available anthelmintic drugs, therefore, there is a foremost problem in treatment of helminths diseases. The control of Helminths in domestic animals is mainly based on the use of anthelmintic drugs which are very expensive. Thus an alternate to these drugs, natural resources are the promising one. Nowadays there is an increasing demand towards natural anthelmintic (2). The drug albendazole is noted for its side effects such as vomiting, nausea, dizziness and gastrointestinal irritation in some patients (3). Seaweeds have been recognized as potential sources of the antibiotic substances. Seaweeds are considered to be the main source of bioactive compounds with a broad range of biological activities, such as antibiotics, antioxidant and anti-inflammatory $(4,5)$. Marine organisms such as marine algae are source material for structurally unique natural products

*Corresponding author:

Email: amutha1994santhanam@gmail.com

http://dx.doi.org/10.20530/IJTA 32 77-80

ISSN 2320-138X (c) 2016 with pharmacological and biological activities (6). Brown algae (Phaeophyta) have shown effectiveness in controlling plant diseases. The laminarin polysaccharide isolated from Laminaria digitata is able to elicit host defense responses in plants (7). Marine organisms especially the macroalgae have a special site as a source of biomedical compounds (8). Hence, this work mainly aims to evaluate the anthelmintic activity of seaweed Padina tetrastromatica extracts in Indian adult earthworm in order to find as an alternative drug and promising source of pharmaceutical agents.

\section{MATERIALS AND METHOD}

\section{Collection of seaweed}

The marine algae Padina tetrastromatica were collected from Mandapam seacoast, Ramanathapuram district, Tamilnadu. The collected samples were rinsed in seawater to remove extraneous materials followed by washing it with double distilled water. The samples were brought to the laboratory in sterile polythene bags. The collected seaweed species was identified taxonomically as Padina tetrastromatica and then used for further analysis. Then the seaweeds were shade dried and blended in electric blender and stored at $4{ }^{\circ} \mathrm{C}$ for further use.

\section{Preparation of Seaweed extract}

The dried powdered seaweed Padina tetrastromatica was extracted with diethyl ether and methanol using soxhlet apparatus for $24 \mathrm{hrs}$. Then the extract was filtered and the filtrate was 


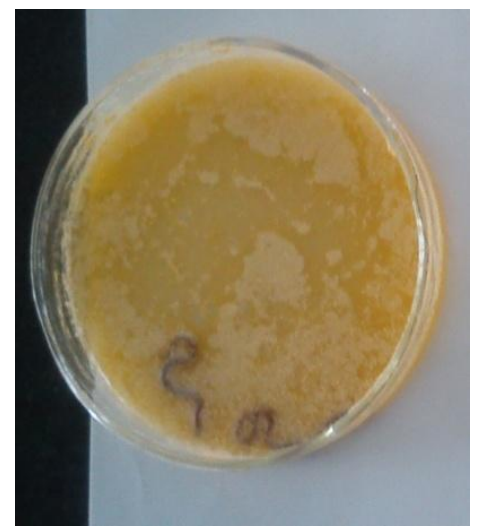

Albendazole $(10 \mathrm{mg} / \mathrm{ml})$

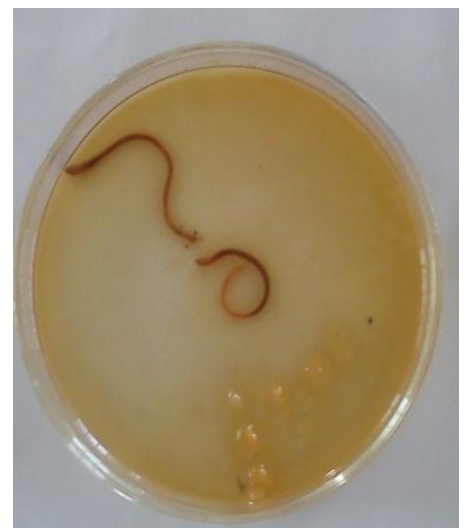

Methanolic extract $(50 \mathrm{mg} / \mathrm{ml})$

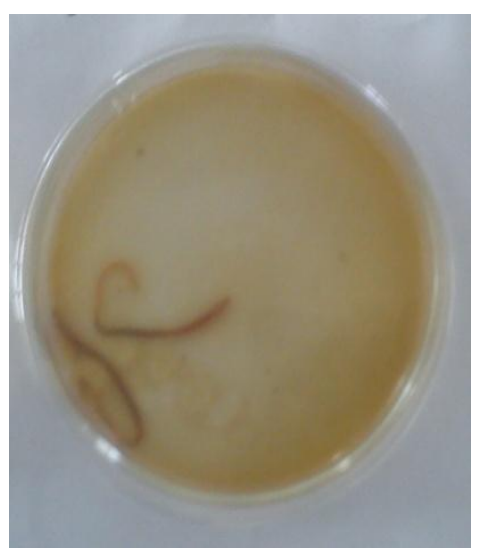

Methanolic extract $(100 \mathrm{mg} / \mathrm{ml})$

Figure 1: Methanolic extract of Padina tetrastromatica and its effect in death of earthworms.

concentrated at $30^{\circ} \mathrm{C}$ under reduced pressure in a rotary evaporator. For aqueous extract preparation, the seaweed powder was extracted with distilled water. The extract was dried under reduced pressure and used for the present study.

\section{Worm Collection and Authentication}

Indian adult earthworms (Pheretima posthuma) were collected from the local Vermicompost shop and washed with normal saline to remove the faecal matter. Experiments were carried out in adult earthworm due to its structural resemblance with the intestinal roundworm parasites of human beings. Indian adult earthworms of about 5-7 cms long were used to evaluate the anthelmintic activity. The earthworms were acclimatized to the laboratory conditions before experimentation. Earthworms were authenticated by the Department of Zoology, Thiruvalluvar University, Vellore, Tamil Nadu.

\section{Administration of Extracts}

The Methanolic, diethyl ether and aqueous extract of seaweed Padina tetrastromatica of two different concentration ( 50,100 $\mathrm{mg} / \mathrm{ml}$ ) were prepared by using normal saline as a suspending agent and volume was made up to $10 \mathrm{ml}$ for respective concentration. Albendazole was used as a standard. All the experimental trails were made in duplicate in order to ensure data. Earthworms of equal size were taken for each concentration and placed in petridish at room temperature.

\section{Anthelmintic Activity}

The anthelmintic activity of methanol, diethyl ether and aqueous extracts of seaweed Padina tetrastromatica was evaluated as per the method reported (9). The test extracts were prepared in different concentrations, and the earthworms were placed in Petri dishes with extracts at room temperature. The time taken for complete paralysis and death were recorded. The time taken for the worms to become motionless was noted as paralysis time; the time death of worm (min) was recorded after noting that worms neither moved when shaken nor when given stimuli followed with fading of their body color. The test results were compared with standard drug Albendazole.

\section{Gas chromatography- Mass Spectrometry}

The composition of the methanolic extract of

Table 1: Anthelmintic activity of Padina tetrastromatica extracts

\begin{tabular}{cccc}
\hline Drug tested & Concentration $\mathbf{( m g} / \mathbf{m l})$ & Paralysis time $(\mathbf{m i n})$ & Death time $(\mathbf{m i n})$ \\
\hline Normal saline & - & - & - \\
Albendazole(standard) & 10 & 14 & 26 \\
Methanolic extract & 50 & 14 & 30 \\
& 100 & 6 & 18 \\
Diethyl ether & 50 & 19 & 39 \\
& 100 & 11 & 24 \\
Aqueous & 50 & 21 & 44 \\
& 100 & 13 & 29 \\
\hline
\end{tabular}




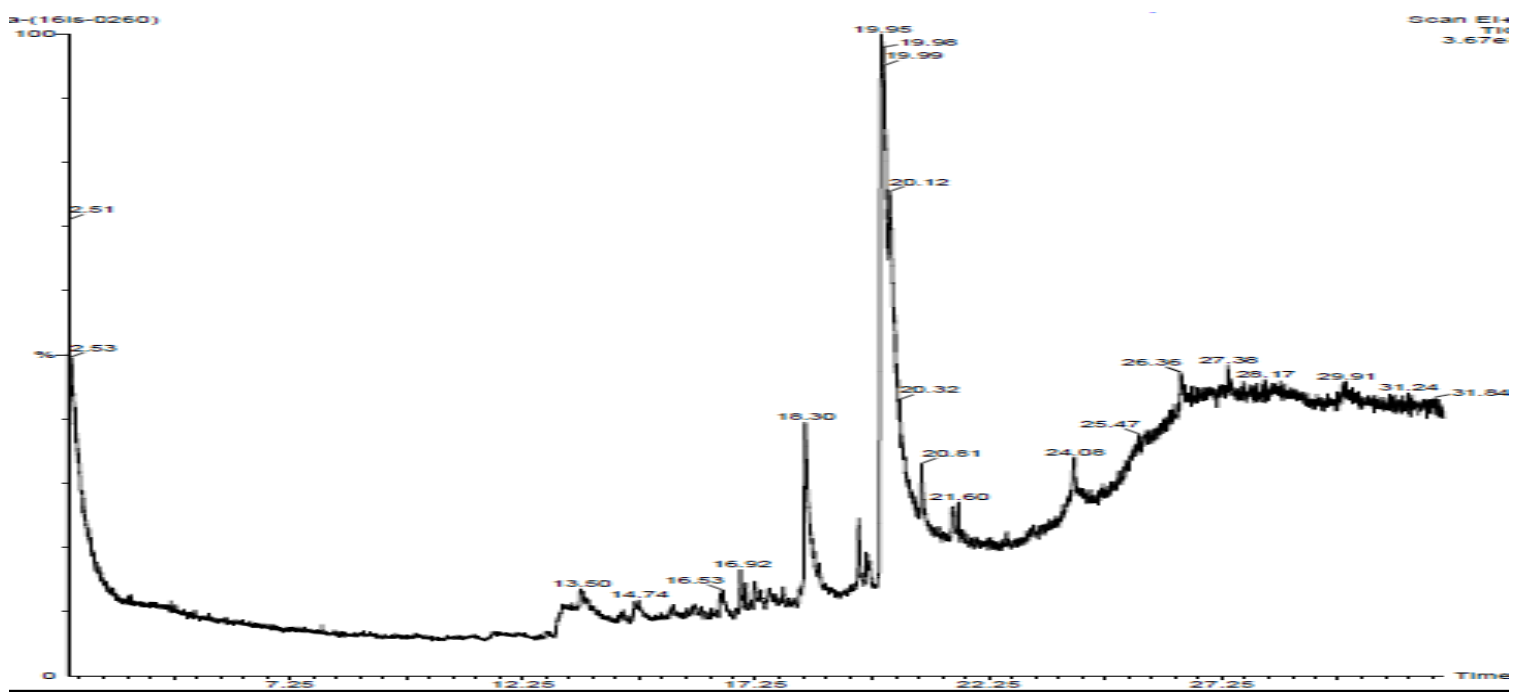

Figure 2 GC-MS chromatogram of Padina tetrastromatica methanolic extract

Table 2 Compounds as revealed by GC-MS analysis from Methanolic extract of Padina tetrastromatica

\begin{tabular}{cc}
\hline S.No & Compounds \\
\hline 1 & N-Hexadecanoic acid \\
2 & Octodecanoic acid \\
3 & Oleic acid \\
4 & Eicosenoic acid \\
5 & Heptadecenoic acid \\
6 & Cyclohexane \\
7 & Oleyl alcohol \\
8. & Trifluoro acetate \\
9. & Tricosenyl formate \\
10. & Nonadecanoic acid \\
\hline
\end{tabular}

seaweed Padina tetrastromatica was obtained using Gas chromatography- mass spectrometry (Agilent 6890 GC coupled MS). The SPME fiber was desorbed in GC injector at $220^{\circ} \mathrm{C}$ for 5 minutes in splitless mode and chromatographic separation was carried out in a capillary column. The temperature was maintained around $60^{\circ} \mathrm{C}$ to $250{ }^{\circ} \mathrm{C}$ at a rate of $2^{\circ} \mathrm{C} \mathrm{min}-1$. Helium was used as a carrier gas. Compound identification was obtained by comparing the retention times with that of the spectral data obtained from NIST library of the corresponding compounds.

\section{RESULTS AND DISCUSSION}

The methanolic extract of seaweed Padina tetrastromatica showed dose-dependent anthelmintic activity as compared with the standard drug albendazole. The data revealed that the paralyzing time of Indian adult earthworms with the dose of 50 and $100 \mathrm{mg} / \mathrm{ml}$ of methanolic extract were found to be 14 and 6 minutes respectively whereas the paralyzing time of diethyl ether and aqueous extracts with the dose of 50 and $100 \mathrm{mg} / \mathrm{ml}$ were found to be 19,11 and 21,13 minutes. This result reveals that the methanolic extract of seaweed shows significant activity when compared with diethyl and aqueous extracts. Many organic solvents like methanol, ethanol has a higher efficiency in extracting compounds when compared with the waterbased solvents. These compounds were found to have many biological activities (10). In order to study the composition of methanolic extract, GCMS has been done. The GC-MS chromatograms showed various compounds present in the methanolic extract of seaweed Padina tetrastromatica (fig 2). The lists of chemical compounds present in the methanolic extract of seaweed Padina tetrastromatica are shown in table 2 . The standard drug albendazole at a dose of $10 \mathrm{mg} / \mathrm{ml}$ causes paralysis in the earthworm in 14 minutes. The death time of earthworm Pheretima posthuma with a dose of 50 and $100 \mathrm{mg} / \mathrm{ml}$ of methanolic extracts of Padina tetrastromatica were found to be 30 and 18 minutes. The death time of earthworms with a dose of 50 and $100 \mathrm{mg} / \mathrm{ml}$ of diethyl ether and aqueous was found to be 39, 24 and 44, 29 minutes. It was found that the higher concentration of the extract became faster due to the paralytic effect and shorter due to the death time of all the earthworms respectively. The anthelmintic activity of the methanolic extract might be attributed to the wide range of chemical classes includes octadecanoic acid, oleic acid, Nhexadecanoic acid, Eicosenoic acid, oleyl alcohol, cyclohexane and Heptadecenoic acid as per the results of GC-MS. 
The anthelmintic effect of extracts is comparable with that of the effect produced by the standard drug albendazole. Marine sources were found to posses many bioactive compounds. Marine products were found to have anthelmintic activity (11). Many species of macroalgae were found to have many compounds like hexadecanoic acid, methyl ester and octadecanoic acid. These compounds are reported of having antimicrobial activity $(12,13)$.

\section{CONCLUSION}

The results of the present study clearly reveals that the methanolic extract of seaweed Padina tetrastromatica have significant anthelmintic activity against Indian adult earthworm Pheretima posthuma. Many researchers were focussing on the therapeutic potential of marine products. The current investigation leads to conclusion that the seaweed Padina tetrastromatica have potent anthelmintic activity. Many phytochemicals were identified in seaweed Padina tetrastromatica methanolic extract by GC-MS analysis. These compounds may be responsible for biological properties including anthelmintic activity. Hence the solvent extract of Padina tetrastromaticat can be used as a anthelmintic agent. Further isolated phytochemicals may serve as lead molecules for development of new drugs as a anthelmintic agent.

\section{REFERENCES}

1. Senthilkumar K, Manivasagan P, Venkatesan J, Kim S-K. Brown seaweed fucoidan: Biological activity and apoptosis, growth signaling mechanism in cancer. International Journal of Biological Macromolecules; 2013 Sep;60:366-74. Available from:

http://dx.doi.org/10.1016/j.ijbiomac.2013.06.030

2. Drahl C, Cravatt BF, Sorensen EJ. Protein-Reactive Natural Products. Angew Chem Int Ed; 2005 Sep 12;44(36):5788-809. Available from: http://dx.doi.org/10.1002/anie.200500900

3. Gogoi B, Kakoti BB, Bora NS, Yadav P. In vitro antihelmintic activity of bark extract of Cinnamomum bejolghota (Buch.-Ham.) in Indian adult earthworm (Pheretima posthuma). Asian Pacific Journal of Tropical Disease; 2014 Sep;4:S924-S927. Available from: http://dx.doi.org/10.1016/s2222-1808(14)60759-3

4. Jing-wen $M$, Wei-ci T. Screening for antimicrobial activities in marine algae from the Qingdao coast, China. Hydrobiologia; 1984 Sep;116-117(1):51720. Available from: http://dx.doi.org/10.1007/bf00027736
5. El Shafay SM, Ali SS, El-Sheekh MM. Antimicrobial activity of some seaweeds species from Red sea, against multidrug resistant bacteria. The Egyptian Journal of Aquatic Research; 2016 Mar;42(1):65$74 . \quad$ Available from: http://dx.doi.org/10.1016/j.ejar.2015.11.006

6. Schwartsmann $G$, da Rocha $A B$, Berlinck RG, Jimeno J. Marine organisms as a source of new anticancer agents. The Lancet Oncology; 2001 Apr;2(4):221-5. Available from: http://dx.doi.org/10.1016/s1470-2045(00)00292-8

7. Klarzynski O, Descamps V, Plesse B, Yvin J-C, Kloareg B, Fritig B. Sulfated Fucan Oligosaccharides Elicit Defense Responses in Tobacco and Local and Systemic Resistance Against Tobacco Mosaic Virus. Molecular Plant-Microbe Interactions; 2003 Feb;16(2):115-22. Available from: http://dx.doi.org/10.1094/mpmi.2003.16.2.115

8. Seghal Kiran G, Manilal A, Sujith S, Selvin J, Shakir C, Premnath Lipton A. Antimicrobial potential of marine organisms collected from the southwest coast of India against multiresistant human and shrimp pathogens. Scientia Marina; 2010 Mar 15;74(2):287-96. Available from: http://dx.doi.org/10.3989/scimar.2010.74n2287

9. Goswami S, Tripathi $P$, Singh A, Pandey A. An in vitro evaluation of anthelmintic activity of Zingiber zerumbet rhizomes and Cucurbita maxima seeds on Pheretima posthuma model: A comparative study. J Pharm Bioall Sci; 2011;3(2):317. Available from: http://dx.doi.org/10.4103/0975-7406.80759

10. H. H. O. Antibacterial activity of extracts of marine algae from the Red Sea of Jeddah, Saudi Arabia. AFRICAN JOURNAL OF BIOTECHNOLOGY; 2012 Sep 4;11(71). Available from: http://dx.doi.org/10.5897/ajb12.780

11. Capon RJ, Vuong D, Lacey E, Gill JH. (-)Echinobetaine A: Isolation, Structure Elucidation, Synthesis, and SAR Studies on a New Nematocide from a Southern Australian Marine Sponge, Echinodictyum sp. . Journal of Natural Products; 2005 Feb;68(2):179-82. Available from: http://dx.doi.org/10.1021/np049687h

12. Ramarao K, Krishnamurthy V. Study of the Preparation and Properties of the Phycocolloid from Hypnea musciformis (Wulf) Lamour from Veraval, Gujarat Coast. Botanica Marina; 1968;11(1-4). Available from: http://dx.doi.org/10.1515/botm.1968.11.1-4.129

13. Alagic S, Stancic I, Palic R, Stojanovic G, Lepojevic Z. Chemical Composition of the Supercritical $\mathrm{CO} 2$ Extracts of the Yaka, Prilep and Otlja Tobaccos. Journal of Essential Oil Research; 2006 Mar;18(2):185-8. Available from: http://dx.doi.org/10.1080/10412905.2006.969906 2 